\section{The diagnosis of art: Diastrophic dysplasia and Hephaistos}

'From Morn

To Noon he fell, from Noon to dewy Eve,

A Summer's day; and with the setting Sun

Dropt from the Zenith like a falling Star,

On LEMNOS th' AEGAEAN Ile'

Milton, Paradise Lost, I: 742-6

The Greek god Hephaistos was, according to Homer, the son of Zeus and Hera. But Hesiod, in his Theogony, says that he was the parthenogenetic son of Hera. A skolion to the Iliad reconciles these two accounts by suggesting that Hera concealed the identity of Hephaistos's father because he was conceived before she and Zeus were married. This befits the modesty for which Hera was known, but it is surprising that Zeus, not a priggish god, nowhere trumpets his paternity. Perhaps he was ashamed of his disabled son.

Hephaistos was born lame in both feet, according to an epithet that various authors gave him-'Amphiguēeis'. We learn in the Homeric Hymn to Apollo that Hera threw him out of heaven soon after his birth because he was deformed, but the Iliad recounts that Zeus threw Hephaistos out of Olympos because he defended Hera from him. As Milton describes, comparing him with Lucifer, Hephaistos fell for a day, eventually landing on Lemnos, where he was cared for by the Sintians. Milton says that he built Pandaemonium, Satan's palace.

Later, in revenge for this ill treatment by his mother, Hephaistos fashioned a magic throne, which held her fast when she sat on it. Only when Dionysos made him drunk did he dissolve the spell. He is also credited with making Achilles' armour and Harmonia's necklace and with fashioning Pandora from clay. Hephaistos married Aphrodite, and of his offspring, Palaimonios is described by Apollonios as being crippled and Periphetes by Apollodoros as being weak in the feet.

Why was Hephaestus lame? We shall propose a diagnosis based on the history and physical examination, using the 6th century BC water-vase illustrated here (Figure 1). We note that depictions of the god changed with time from short and deformed to tall and normal, ${ }^{1}$ and that depending on the history and examination one chooses to adopt, different diagnoses are possible - that is the fun of the game. We shall assume that Hephaistos was lame from birth, that both feet were affected, and that his affection was hereditary. We shall also invoke other features in the figure shown here - the abnormal upper limbs, the short stature, and some facial features.

We rule out bilateral congenital talipes equinovarus; ${ }^{2}$ it has a strong multifactorial hereditary component but no upper limb features or short stature. The latter also rules

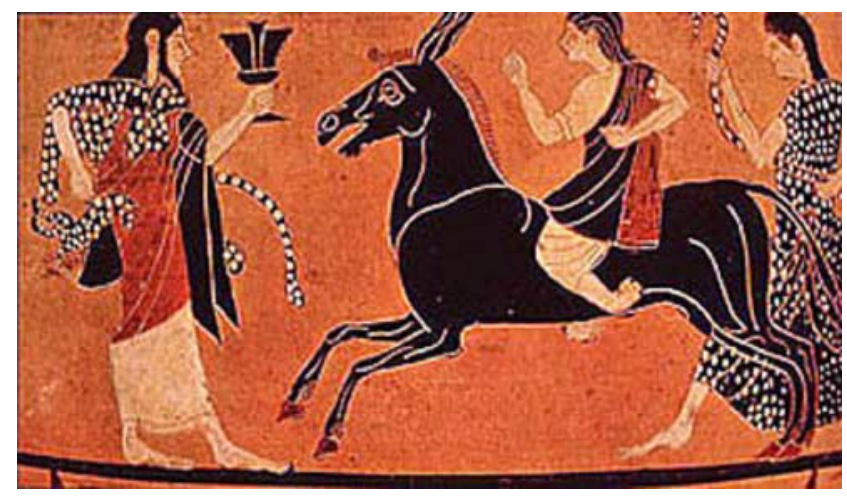

Figure 1 Hephaistos (mounted) with Dionysus (left) as depicted on a sixth century BC hydria (water-vase). (Image reproduced in colour online.)

equinovarus occurs, and which could explain the elbows fixed in flexion. Another suggested diagnosis, achondroplasia, would not explain the foot deformities; this diagnosis is based on earlier images of the god, evoking Egyptian depictions of deities such as Ptah, Bes and Harpocrates. ${ }^{1}$

We also rule out an acquired peripheral neuropathy secondary to arsenic poisoning, an affection of smelters. ${ }^{3}$ It may be that this afflicted models for the artists who depicted Hephaistos, if for example they were smelters who had been exposed to arsenic, but it does not fit the history we have proposed. Furthermore, it is more likely that Hephaistos became a smith because he hobbled rather than the other way round; in primitive societies a lame man with strong arms would be highly suited for smithery, other common occupations being ruled out.

The diagnosis that we favour, after Silverman, ${ }^{4}$ is diastrophic dysplasia, short-limbed dwarfism with bilateral rigid foot deformities, such as hindfoot equinovarus and forefoot adductus resembling clubfeet; upper limb involvement with contractures of the elbows leading to loss of extension but no loss of power; and progressive scoliosis, hip, and knee flexion contractures, which can cause stooping and limping. It has an autosomal recessive pattern of inheritance, and may have been passed on to his children. There are lethal and severe variants, but there is also a mild variant, with a normal lifespan. Perhaps the blot below Hephaistos' left eye is a haemangioma, another feature of the disease. And his ear may be misshapen (it is different from the ears of the others in the picture), due to typical cystic change. An alternative diagnosis is pseudodiastrophic dysplasia, in which elbow dislocations are prominent, ${ }^{5}$ but very few cases have been described.

Competing interests None declared.

\section{Manoj Ramachandran ${ }^{1}$ Jeffrey K Aronson ${ }^{2}$}

${ }^{1}$ Fellow in Paediatric and Young Adult Orthopaedics, The Royal National Orthopaedic Hospital, Stanmore, Middlesex and Great Ormond Street Children's 
Hospital, London, UK; ${ }^{2}$ Reader in Clinical Pharmacology, Department of Clinica Pharmacology, Radcliffe Infirmary, Woodstock Road, Oxford, UK

Correspondence to: Manoj Ramachandran

E-mail: manojorthopod@gmail.com

\section{REFERENCES}

1 Aterman K. Why did Hephaestus limp? Am J Dis Child 1965;109:381-92

2 Bazopoulou-Kyrkanidou E. What makes Hephaestus lame? Am J Med Genet 1997;72:144-55

3 Aterman K. From Horus the child to Hephaestus who limps: a romp through history. Am J Med Genet 1999;83:53-63

4 Silverman FN. Re: 'Why did Hephaestus limp?' Am J Dis Child 1965;109:392

5 Eteson DJ, Beluffi G, Burgio GR, Belloni C, Lachman RS, Rimoin DL. Pseudodiastrophic dysplasia: a distinct newborn skeletal dysplasia. J Pediatr 1986;109:635-41

\section{Spinal cord injury: progress, promise and priorities}

Committee on Spinal Cord Injury, Board of Neuroscience and Behavioral Health Institute of Medicine of the National Academies 343 pp Price £29.99 ISBN 0-309-09585-9

Washington: National Academic Press

The tragic accident that left Christopher Reeves quadriplegic, his considerable efforts to cope with this utilizing all possible methods, and the publicity he generated, resulted in a much greater awareness of the problems faced by patients with spinal cord injuries, and was a powerful stimulus to research in this field.

This monograph is dedicated to his memory and has been produced by an expert committee, chaired by Richard $\mathrm{T}$ Johnson, in collaboration with the board of Neurosciences and Behavioral Health, at the request of the New York State Spinal Cord Injuries Research Board.

There are about 11000 spinal cord injuries a year in the USA and nearly 250000 patients living with these injuries-mostly young men in their late twenties and early thirties. The total annual cost in the USA is about US\$10 billion. This puts spinal cord injury behind multiple sclerosis_-but ahead of epilepsy, Parkinson's disease, Alzheimer's disease and stroke-in terms of annual cost per patient.

The pathophysiology of spinal cord injury and, in particular, factors which determine its progression are discussed in detail. Little can be done to alter the instant effect of injury, except for prophylaxis. However, the hope is that there might be effective protocols for the immediate management which might reduce the risk of further damage and perhaps arrest the development of the lesion, and hence reduce the long-term disability. At present, management is largely that of the complications including pain, spasticity, bladder and bowel dysfunction, autonomic disturbance and pressure sores; all of which are discussed in separate sections. Prospects for neuronal repair and regeneration remain theoretical and experimental.

Among the nine appendices are the outcome of 13 published clinical trials of methylprednisolone and an analysis of 321 published clinical trials and studies from 1998 to 2003, grouped by system or clinical problem (acute care, bladder and bowel, bone density, cardiovascular, exercise and locomotion, electrical and magnetic stimulation, imaging, psychological factors, spasticity, neurological responses, outcome measures, pain, physiological responses, respiration, syringomyelia and pressure sores).

This monograph will be essential reading for all those working in the field of spinal cord injury and an invaluable reference source. It should also stimulate research granting bodies and the Government to take a greater interest in research on spinal cord injuries, which is clearly underfunded and under-resourced.

\section{D O'Brien}

E-mail: obrmd@btinternet.com 